\title{
Amy Ward new Editor-in-Chief
}

This is my final issue of ORL. I am very pleased that Amy Ward has agreed to become Editor-in-Chief of the journal starting April 1, 2021.

Operations Research Letters was founded in 1981 by George Nemhauser. The journal has always been committed to the rapid review and fast publication of short contributions to the field, where quality, originality, relevance and clarity are the only criteria for accepting papers for publication. Our traditional strength is in methodology, including theory, modelling, algorithms and computational studies. In the past two decades, next to the broad areas of optimization and stochastic models, game theory has emerged as an integral subject area of the journal.

Since 2002 , we received about 10,000 papers and published 2,044 of these. I wish to express my sincere thanks to the authors who allowed us to review their work and to the 201 area and associate editors and the countless referees who did all the hard work. Five colleagues joined the team in 2002 and stayed on board for nineteen years: Xiuli Chao, Cor Hurkens, Sridhar Seshadri, Jiri Sgall, and Gerhard Woeginger. I am very grateful to the staff of Elsevier for their trust and especially to the Journal Manager, Radha Ganesan, for her untiring help and quiet efficiency.

It has been a privilege to work with all of you, and it is a pleasure to express my confidence in my successor. I wish Amy every success in continuing our tradition and exploring new avenues.

Jan Karel Lenstra Centrum Wiskunde \& Informatica, Amsterdam, Netherlands E-mail address: Jan.Karel.Lenstra@cwi.nl.

Available online $\mathrm{xxxx}$ 